\title{
Towards a collaboration context ontology
}

\author{
Siying Li \\ Sorbonne universités, Université de \\ technologie de Compiègne \\ CNRS UMR 7253, HEUDIASYC, 60203 \\ Compiègne, France \\ siying.li@utc.fr
}

\author{
Marie-Hélène Abel \\ Sorbonne universités, Université de \\ technologie de Compiègne \\ CNRS UMR 7253, HEUDIASYC, 60203 \\ Compiègne, France \\ marie-helene.abel@utc.fr
}

\author{
Elsa Negre \\ Paris-Dauphine University, PSL \\ Research University \\ CNRS UMR 7243, LAMSADE, 75016 \\ Paris, France \\ elsa.negre@dauphine.fr
}

\begin{abstract}
Collaboration occurs almost everywhere. The challenge today is how to succeed it. In addition, the development of digital technologies requires higher demands to succeed in collaborations and thus makes the challenge more difficult to handle. To address it properly, we study impacting factors that affect the success of collaborations and integrate them into collaboration context ontology to analyze and evaluate the success of collaborations supported by digital technologies. In this article, we present the collaboration context ontology that we have developed and show why and how it can be used.
\end{abstract}

Keywords-Context modeling, collaboration context, ontology.

\section{INTRODUCTION}

As an effective way of working together [17], collaboration becomes popular [16]. Particularly, successful ones can produce beneficial results [17]. However, collaboration is neither easy to achieve nor guaranteed to succeed [15]. Hence, the research on how to succeed in collaborations interests people in health care [12], community organizations [21], and academy [17]. One of the current issues is how to make collaboration as successful as possible. Besides, diverse digital technologies are now available to facilitate collaborations, such as virtual reality (VR) [30], and computer technology [31]. Their rapid developments require higher demands to succeed in collaborations, which led to the emergence of collaborative network [32] and even make the issue more complex to solve.

In order to achieve collaborations as successfully as possible, various factors that can influence the success of collaborations must be considered, such as collaborators (members) $[15,17]$, resources $[12,17]$, and goals [15, 17, 21]. In addition to concentrating only on the factors, considering them within the context is necessary to form and thus succeed collaborations [18]. Therefore, we are interested in integrating these factors into a collaboration context model to analyze and evaluate the success of the collaboration. In addition, to support collaborations using digital technologies, it is essential to allow the machines that apply these technologies to access their contexts [20]. To that end, we focus on a machine-interpretable $[11,26]$ and reasonable [24] knowledge representation - ontology, and using it to construct the collaboration context model - collaboration context ontology.

The reminder of this paper is constructed as follows. Section II studies the impacting factors of successful collaborations and makes a survey of approaches to model context. The collaboration context ontology is presented in Section III. We then discuss how to use the ontology in different phases of collaborations. Finally, some conclusions and future work are put forward in Section V.

\section{RELATED WORK}

In this section, we analyze the impacting factors of successful collaborations and discuss the collaboration context. Moreover, we study different approaches of context modeling.

\section{A. The impacting factors of succuessful collaboration and collaboration context}

Kotlarsky and Oshri [22] consider a successful collaboration as a process "through which a specific outcome is achieved". Oliveira et al [21] also agree with this view and discuss the degree of success in collaborations in terms of the teamwork product. With a shared goal to achieve $[1,15,17$, 21], a collaboration involves two or more people and comprises a set of human actors' actions on behalf of the corresponding collaborator [1]. If the interactions between these collaborators are supported by computer network to form a collaborative network ${ }^{1}$, collaborators can "achieve goals that would not be possible or would have a higher cost if attempted by them individually" [32].

In order to establish the success of collaborations, different factors can be taken into account. Some researches have classified the impacting factors into groups (categories) (see Table I). San Martín-Rodríguez et al. [12] study three types of factors for interprofessional collaborations in health care. Patel et al. [15] aim to frame a collaborative working model using eight groups of factors. Mattesich and Monsey [17] find 19 impacting factors and classify into six categories by reviewing studies on collaboration.

Other research works have identified factors influencing the success of collaboration (see Table II). Hara et al. [14] focus on the scientific collaboration and summarize four factors. Bruneel et al. [13] investigate three key factors of University-Industry collaborations. Camarinha-Matos and Afsarmanesh [34] highlight main elements in Virtual Organization Breeding Environment $\left(\mathrm{VBE}^{2}\right)$, which is a subtype of collaborative network [36].

\footnotetext{
1 "A collaborative network $(\mathrm{CN})$ is constituted by a variety of entities (e.g., organizations and people) that are largely autonomous, geographically distributed, and heterogeneous in terms of their: operating environment, culture, social capital, and goals." [32]

${ }^{2} \mathrm{VBE}$ is a breeding environment with the main goal of increasing both VBE members' chances and preparedness of collaboration in potential Virtual Organizations (VOs) [35]. Here, VO is "an alliance comprising a set of (legally) independent organizations that share their resources and skills, to achieve their common mission / goal".
} 
TABLE I. SUMMARY OF IDENTIFIED IMPACTING FACTORS(WITH ITS GROUPS) OF SUCCESSFUL COLLABORATION

\begin{tabular}{|c|c|c|}
\hline & Group & Factors \\
\hline \multirow{3}{*}[12]{} & $\begin{array}{l}\text { Interactional } \\
\text { factors }\end{array}$ & $\begin{array}{l}\text { Willingness to collaborate; Trust; } \\
\text { Communication; Mutual respect. }\end{array}$ \\
\hline & $\begin{array}{l}\text { Organizational } \\
\text { factors }\end{array}$ & $\begin{array}{lr}\text { Organizational } & \text { structure; } \\
\text { Organization's } & \text { philosophy; } \\
\text { Administrative support; Team sources; } \\
\text { Coordination and communication } \\
\text { mechanisms. }\end{array}$ \\
\hline & $\begin{array}{l}\text { Systemic } \\
\text { factors }\end{array}$ & $\begin{array}{l}\text { The social system; The professional } \\
\text { system; The educational system. }\end{array}$ \\
\hline \multirow{7}{*}[15]{} & Context & $\begin{array}{l}\text { Culture; Environment; } \quad \text { Business } \\
\text { climate; Organizational structure. }\end{array}$ \\
\hline & Support & $\begin{array}{l}\text { Tools; Networks; Training; Team } \\
\text { building; Knowledge management; } \\
\text { Error management. }\end{array}$ \\
\hline & Tasks & Type; Structure; Demands. \\
\hline & $\begin{array}{l}\text { Interaction } \\
\text { Processes }\end{array}$ & $\begin{array}{l}\text { Learning; Coordination; } \\
\text { Communication; Decision-making. }\end{array}$ \\
\hline & Team & 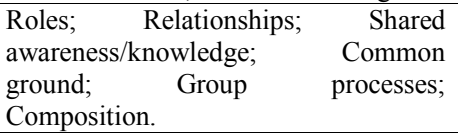 \\
\hline & Individuals & $\begin{array}{l}\text { Skills; Psychological factors; } \\
\text { Wellbeing. }\end{array}$ \\
\hline & $\begin{array}{l}\text { Overarching } \\
\text { Factors }\end{array}$ & $\begin{array}{l}\text { Trust; Conflict; Experience; Goals; } \\
\text { Incentives; Constraints; Management; } \\
\text { Performance; Time. }\end{array}$ \\
\hline \multirow{6}{*}{ [17] } & Environment & $\begin{array}{l}\text { History of collaboration in the } \\
\text { community, Collaborative group seen } \\
\text { as a leader in the community, } \\
\text { Political/social climate favorable }\end{array}$ \\
\hline & Membership & $\begin{array}{l}\text { Mutual respect, understanding and } \\
\text { trust; Appropriate cross-section of } \\
\text { members; Members: collaboration as } \\
\text { in their self-interest; Ability to } \\
\text { compromise }\end{array}$ \\
\hline & $\begin{array}{l}\text { Process/ } \\
\text { Structure }\end{array}$ & $\begin{array}{l}\text { Members share a stake in both process } \\
\text { and outcome; Multiple layers of } \\
\text { decision-making; } \\
\text { Development of clear roles and policy } \\
\text { guidelines; Adaptability }\end{array}$ \\
\hline & Communication & $\begin{array}{l}\text { Open and frequent communication; } \\
\text { Established informal and formal } \\
\text { communication links. }\end{array}$ \\
\hline & Purpose & $\begin{array}{ll}\text { Concrete, } & \text { attainable goals and } \\
\text { objectives; } & \text { Shared vision; Unique } \\
\text { purpose } & \end{array}$ \\
\hline & Resources & Sufficient funds; Skilled convener. \\
\hline
\end{tabular}

TABLE II. SUMMARY OF IDENTIFIED IMPACTING FACTORS OF SUCCESSFUL COLLABORATION

\begin{tabular}{|l|l|}
\hline & \multicolumn{1}{|c|}{ Factors } \\
\hline$[14]$ & $\begin{array}{l}\text { Personal compatibility; research work connections; } \\
\text { Incentives; Socio-technical infrastructure. }\end{array}$ \\
\hline$[13]$ & $\begin{array}{l}\text { Experience of collaboration; Breadth of interaction channels; } \\
\text { Inter-organizational trust. }\end{array}$ \\
\hline$[34]$ & $\begin{array}{l}\text { VBE; VBE member; VO; Profile; History; Evidence; Bag of } \\
\text { assets; Management system; VBE governance; Value } \\
\text { system; Trust system. }\end{array}$ \\
\hline
\end{tabular}

In Table I, the groups of factors are so diverse that there is no identical group. Besides, in all these research works (Table I and II), we can categorize factors according to their links into two classes: (1) distinguished factors such as, 'research work connections' [14], 'the educational system' [12], and 'wellbeing' [15]; (2) shared factors (summarized in
Table III), which imply the common features of the collaboration but distributed in different groups.

All these factors provide characteristic information of successful collaborations.

TABLE III. SUMMARY OF THE SHARED FACTORS

\begin{tabular}{|l|l|}
\hline \multicolumn{1}{|c|}{ Factor } & \multicolumn{1}{c|}{ References } \\
\hline Goal & {$[15],[17]$} \\
\hline Interaction & {$[12],[13],[14],[15],[17]$} \\
\hline Communication & {$[12],[15],[17]$} \\
\hline Decision-making & {$[15],[17]$} \\
\hline Coordination & {$[12],[15],[17]$} \\
\hline Members & {$[15],[17],[34]$} \\
\hline Relationships between members & {$[15],[17]$} \\
\hline Members' abilities & {$[14],[15],[17],[34]$} \\
\hline Sharing among members & {$[15],[17]$} \\
\hline Resources ${ }^{3}$ & {$[12],[15],[17]$} \\
\hline Trust & {$[12],[13],[15],[17],[34]$} \\
\hline
\end{tabular}

Besides, Patel et al. [15] define the group 'context' that considers factors like cultural, environmental, business, and organizational to determine the type of individuals, teams, and tasks during collaborations. These factors do not define the collaboration itself but are directly linked to it and its success. "Context is any information that can be used to characterize the situation of an entity. An entity is a person, place, or object that is considered relevant to the interaction between a user and an application, including the user and applications themselves" [2]. As part of our research, we focus on the collaboration context: in the previous definition [2], we consider the entity is 'collaboration' [1] in a digital ecosystem, which is emerged from business ecosystem [33] and thus is considered as a VBE according to [35].

Defining a corresponding model could contribute to improve the comprehension of collaboration as well as facilitate its success.

\section{B. Approaches of context modeling}

A large number of context models have been proposed with the development of context-aware applications. Based on the scheme of data structures, Strang and Linnhoff-Popien [6] classify six approaches of context modeling, as follows: Key-value model, Markup model, Graphical model, Objectoriented model, Logic-based model, and Ontology-based model. Moreover, Bettini et al. [7] add a spatial model that concentrates on the location information.

Besides, the development of digital technologies, particularly computer technology, offers better communication opportunities, provides improved monitoring and awareness possibilities for the collaborators to coordinate their activities [29], and even results in major enhancements to the productivity of collaborations [28]. For example, VR is used to set a shared space of collaboration [30], while computer technology could support remote collaborations between users [31] and help to construct collaborative networks [32]. Thus, in our research, we

${ }^{3}$ Particularly, resources can be of multiple types, such as tools [15], documents [16]. 
consider choosing an approach that could enable the context model to support collaborations using digital technologies.

Among all the approaches, as a tool for organizing and contextualizing knowledge [23], ontologies are applied in considering context as a specific type of knowledge [7]. Based on the requirements of our research, machineinterpretability and automated reasoning make ontology the best choice to identify and assess the state of collaboration based on its contextual information.

Firstly, as shared and common knowledge (understanding) of an area [9, 24, 25], ontologies could be represented by multiple languages. All these ontological languages are readable [25], usable [24] and thus interpretable $[11,26]$ to the machines.

Secondly, according to [24], expressed in logic-based languages, ontologies enable automated reasoning to be carried out, and thus to provide advanced services to intelligent applications. Moreover, ontology allows augmenting, enriching and synthesizing context using available reasoning mechanisms [19].

Besides, ontologies have already been used to conceptualize and formalize context. Gu et al. [9] propose an ontology-based context model in intelligent environment. Moreover, $\mathrm{Yu}$ et al. [27] model user context for contextaware e-learning. Chen et al. [20] also use ontology to provide a set of terms for describing context knowledge in a shared-context environment. However, to the best of our knowledge, there is no existing ontology about collaboration context. Therefore, we propose to build a collaboration context ontology based on our previous work.

\section{COLLABORATION CONTEXT ONTOLOGY}

Based on the discussion in Section II, we identify eight groups of factors in the collaboration context ontology, MEMORAe-Collaboration-Context (MCC). We then illustrate the integrations in MCC with other existing ontologies. Finally, the process of its modeling will be explained.

\section{A. Factors of collaboration context}

Based on [2] we define a collaboration context as any information that can be used to characterize the situation of collaboration over a given period [1]. From the discussion in section II.A, we identify a set of impacting factors of successful collaboration to characterize the state of a collaboration. We consider these factors as contextual factors

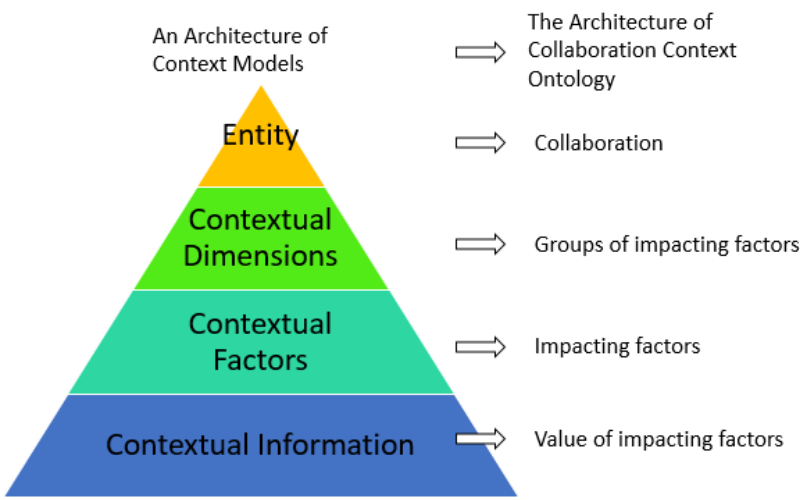

Fig. 1. From an architecture of context models to the architecture of the collaboration context model of collaboration. Their values are represented by corresponding contextual information [8]. Grouping these contextual factors could specify a measurable dimension [1], such as the groups of factors in Table I.

These three interrelated concepts (contextual information, factor and dimension) could form an architecture of context models [3] (see Fig. 1). For collaboration context ontology, the architecture obtained by the transformation is shown on the right side of Fig. 1. It is then a matter to define groups, corresponding factors and their values to construct the ontology.

Based on the analysis of the factors (in section II.A), eight groups of factors are identified to establish and measure the success of collaboration (see Table IV) [3]. The first four are inspired by categorizing the shared factors (Table III) and summarizing other factors (Table I and II). Next two groups presents the temporal and spatial context of a collaboration. The group 'relation' represent the factors of all the relationships that can be established with other collaborations. The final one specifies a degree of satisfaction from a collaborator.

TABLE IV. GROUPS OF IMPACTING FACTORS OF THE COLLABORATION CONTEXT

\begin{tabular}{|c|c|}
\hline Groups & Factors \\
\hline Goal & Shared objectives; Desired outcomes \\
\hline Collaborator & $\begin{array}{l}\text { Experiences of collaborations; Competencies; } \\
\text { Demographic information; Relations with } \\
\text { other persons (e.g. trusted collaborators and } \\
\text { contacts) }\end{array}$ \\
\hline Activity & $\begin{array}{l}\text { Interaction; Communication; Coordination; } \\
\text { Decision-making; Sharing resources }\end{array}$ \\
\hline Resource & Tools; Technology; Document \\
\hline Time & Start time; End time \\
\hline Location & Type (Physique or digital); Address \\
\hline Relation & Related collaboration(s) \\
\hline Satisfaction & $\begin{array}{l}\text { Degree of personal satisfaction about } \\
\text { collaborations; Evaluation and comments } \\
\text { about collaborations }\end{array}$ \\
\hline
\end{tabular}

\section{B. Integration with existing ontologies}

To construct MCC (see Fig. 2), we reuse six existing ontologies, as follows: MEMORAe-core 2 (MC2) [4], MEMORAe-SoIS (MS) [5], User Profile Ontology (UP) ${ }^{4}$, $\mathrm{FOAF}^{5}, \mathrm{PROV}^{6}$, and $\mathrm{SIOC}^{7}$. Specially, MC2 is to support the collaboration between users in a digital working environment [4]. As an extension model of $\mathrm{MC2}$, MS provides assistances for the collaboration happening in a more complex environment, System of Information System (SoIS) [5]. MC2 and MS have been implemented into the digital platform, MEMORAe. $\mathrm{UP}^{2}$ aims at describing information in user profiles. Other three ontologies are already used by MC2 and MS to define the vocabularies related to the collaboration. The eight groups of factors are specified with rectangles and shown in Fig. 2 (except the group 'collaborator' is shown in Fig. 3 with details): a group

\footnotetext{
${ }^{4}$ http://iot.ee.surrey.ac.uk/citypulse/ontologies/up\#

${ }^{5}$ http://xmlns.com/foaf/spec/

${ }^{6}$ https://www.w3.org/TR/prov-overview/

${ }^{7}$ https://www.w3.org/Submission/sioc-spec/
} 


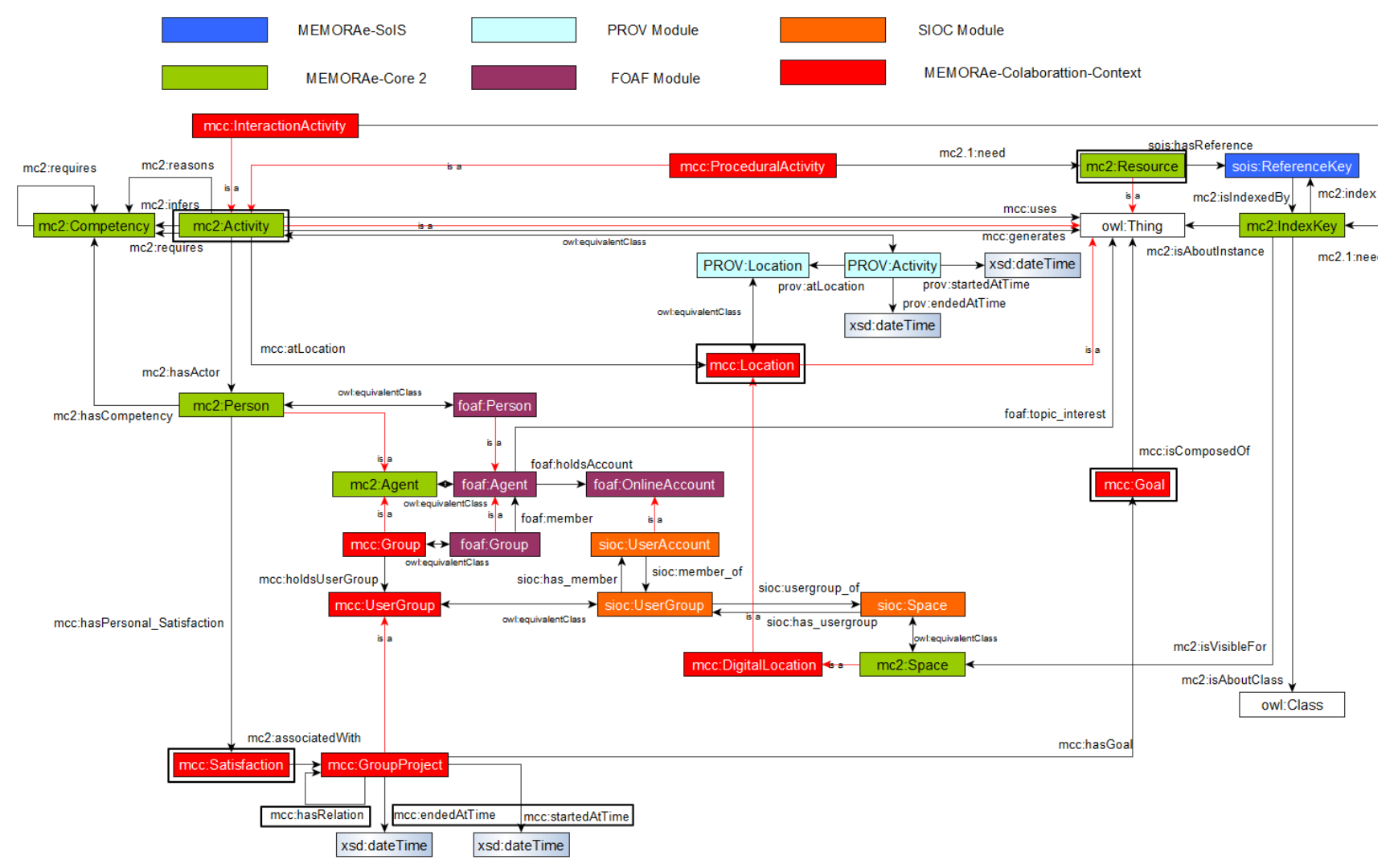

Fig. 2. Eight groups of impatcing factors in $\mathrm{MC} 2.1$.

project is defined for a time, has a goal and at least two members/collaborators who have competencies, realize activities in a location using resources and have a satisfaction feeling about the collaboration inside the group.

\section{Modelling}

This sub-section presents a scenario of collaboration. We then explain how MCC is constructed and how it can be used to present the collaboration in our scenario.

1) A scenario of collaboration

Emma is a $\mathrm{PhD}$ student on the computer science in $\mathrm{X}$ laboratory, supervised by a professor, Marie. Her thesis is about context-aware applications. She collaborated with two engineers, Lucie and Lisa, to build a context-aware application using AngularJS and Bootstrap, from 01/07/2018 to $20 / 11 / 2018$. This application is a part of her $\mathrm{PhD}$ research. Lucie is a young engineer. She finished an internship on building an editing prototype for a company. Then she started her work in X laboratory with the context-aware application project. Moreover, Lisa is an experienced senior engineer in X laboratory. She has worked for 5 years and helped a lot of students and researchers on their projects. She is an expert in a variety of programming languages, especially in web applications.

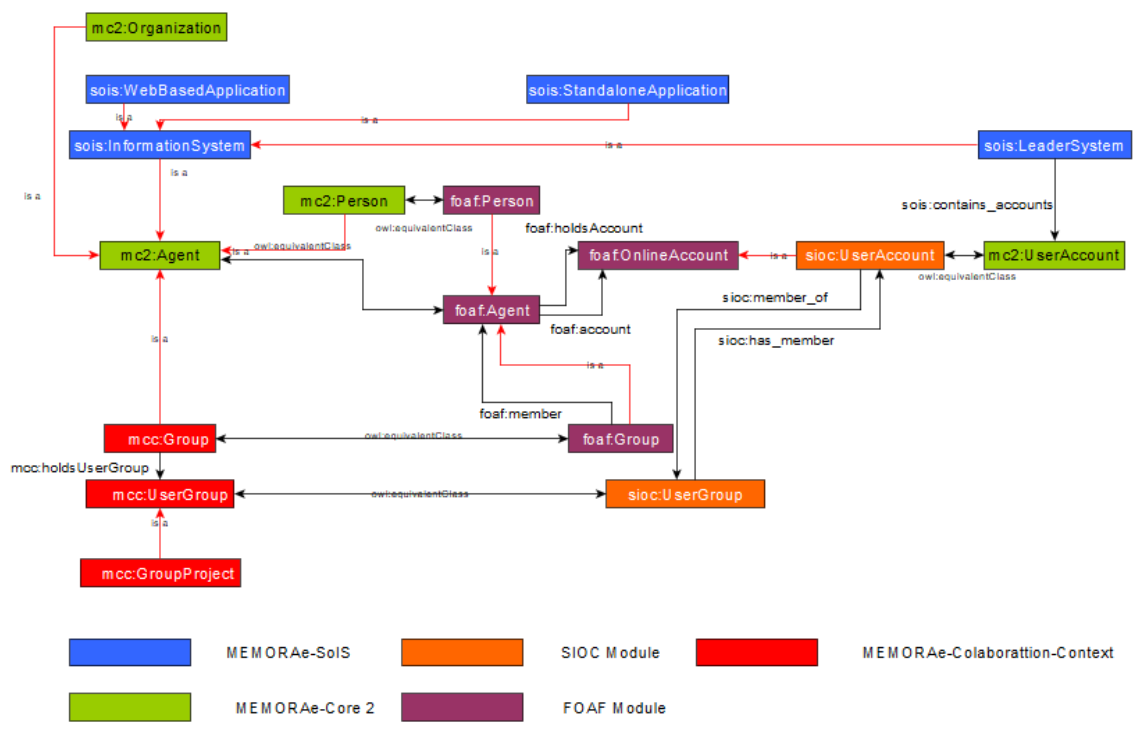

Fig. 3. The group 'collaborator' in MCC. 


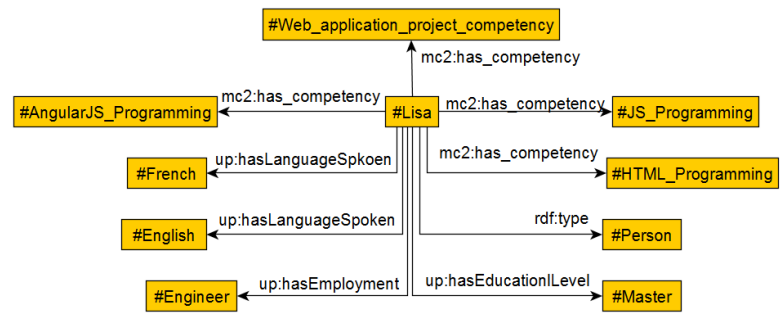

Fig. 4. Lisa's profile.

2) MEMORAe-Collaboration-Context (MCC)

MCC defines collaboration using a class of user group, mcc:GroupProject (shown in Fig. 2), which is a mcc:UserGroup. In our scenario, the context-aware application project is represented by an instance of mcc:GroupProject. This project group will provide a sharing space for Emma, Lucie and Lisa to interact with each other and access to the available resources. Every project group is held by a mc2:Group, equivalent to foaf:Group ${ }^{2}$. This class represents a group in real world. The members in a such group might collaborate multiple times on different projects, while the members in a mcc:GroupProject are limited to collaborate only for the project.

A mcc:GroupProject is considered as a set of members (at least two) who have a common goal to achieve and hold their own user accounts. In the above scenario, the new mcc:GroupProject created contains the user accounts of Emma, Lucie and Lisa, rather than themselves. Surrounding mcc:GroupProject, the eight groups ${ }^{8}$ (Table IV) are modeled as shown in Fig. 2. Note that MC2 and MS have partially defined the vocabularies of four groups: Collaborator, Activity, Resource and Location.

Firstly, the common goal can be anything (simple or composed), owl:Thing. The project has to finish on $15 / 11 / 2018$

Then, MCC applies MC2, MS, FOAF, and SIOC to model the group - collaborator (see Fig. 3). A mcc:Group could create multiple user groups where all the members hold a user account. Moreover, MCC applies UP and MC2 to describe collaborator's profile, including their personal information and competencies. In our scenario, they could consult Lisa's profile (see Fig. 4) to arrange her activities in the collaboration.

As for the activities, MCC combines the two activities modules (in MC2 and MS) together to collect users' traces. Regarding resources, MC2 defines it as "vectors of information" and classifies it into simple and composite

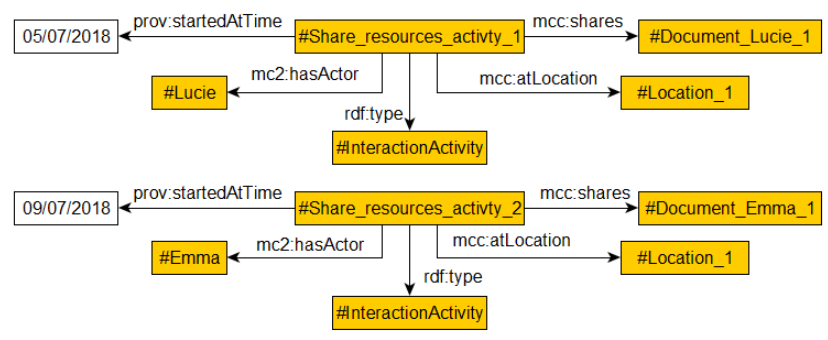

Fig. 5. Sharing resources activity in the project.

${ }^{8}$ Seven groups are marked in blue rectangles, except the group 'collaborator' which will be explained in Fig. 3 with morel details.

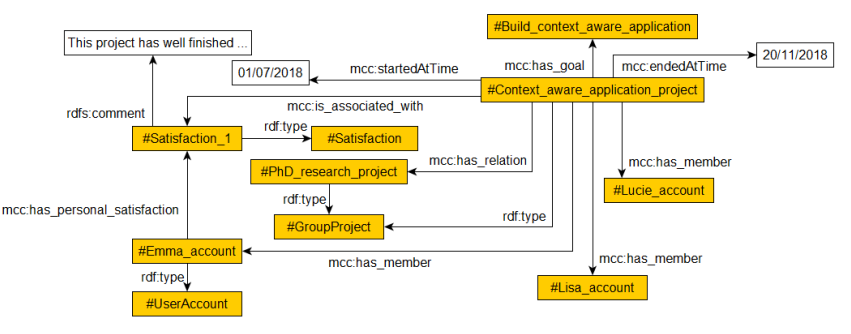

Fig. 6. Time, relation and satisfaction representations in our scenario.

resource [5]. Based on the factors in Table IV, MCC integrates three types of simple resources: tool, technology, and document. Adding other information about location, MCC could track what resources are used in which activity at which location (see Fig. 5).

For other three groups (time, relation and satisfaction), they are all related directly to mcc:GroupProject. With these groups, MCC is able to record collaborator's personal feedback and allow analyzing the relations between different collaborations. In our scenario, the application project is a part of Emma's PhD research with her professor (see Fig. 6).

Using MCC, the success of the collaboration depends on whether the common goal is achieved or not, while other seven groups could be used to examine the effectiveness of the success, such as collaborators' contributions, the productivities of the activities effected, and the values of the resources used.

\section{DISCUSSION}

MCC could contribute to clarify the characteristics of a collaboration and its context in different phases: preparation, collaboration itself and debriefing.

To prepare a collaboration, with a well-determined goal, MCC could be used to find suitable members according to their past activities and profile information. Moreover, MCC serves to find out whether the collaborators have all the competencies required to finish the shared objectives and achieve the desired outcomes.

During a collaboration, MCC could help collaborators to check: whether their collaboration is going smoothly right now; do they need to ask help for someone else out of their project group; do they need to learn something because of the lack of competencies. MCC makes it possible to identify the weak and strong points during a collaboration and then let collaborators set up strategies to deal with the issues.

After a collaboration is finished, MCC could identify whether the initial goal is well reached or not; are all the desired results obtained or not. It could also update the collaborators' profile and activities history to let others know what this collaboration brings personally to the members, such as new competencies, new spoken language.

\section{CONCLUSION AND FUTURE WORK}

In this article, we focus on the collaboration context and propose to construct a collaboration context ontology to assess and facilitate the success of collaborations. Based on the related literature in Section II, we have explained the reasons why collaboration context could help to succeed in collaborations and justified the choice of ontology among the different context modeling approaches. Then we have 
presented the collaboration context ontology that we have built by so far and demonstrate it with a scenario. We finally have discussed the usages of the ontology in different phases of a collaboration.

Our research perspectives include the implementation of MCC into a digital environment in order to support real collaborations that are more complicated than the limited scenario we illustrated, as well as the development of a context-aware recommender system by using the contextual information of collaboration. The recommendation algorithms are also needed to generate recommendations.

\section{REFERENCES}

[1] S. Li, M.H. Abel, and E.Negre, "Contact and collaboration context model," In $4^{\text {th }}$ International Forum on Research and Technologies for Society and Industry, RTSI 2018, unpublished.

[2] A.K. Dey, "Understanding and using context," Personal and ubiquitous computing, Springer-Verlag, volumn 5, number 1, pp. 4-7, 2001

[3] S. Li, M.H. Abel, and E. Negre, "Modèle de contexte de collaboration: pour qui, pourquoi, comment?" In 29es Journées Francophones d'Ingénierie des Connaissances, IC 2018, pp. 229-243, 2018.

[4] N. Wang, "Towards a competency recommender system from collaborative traces," PhD dissertation, Université de Technologie de Compiègne, 2016.

[5] M. Saleh, "Digital ecosystem towards a System of Information Systems," PhD dissertation, Université de Technologie de Compiègne, 2018, in press.

[6] T. Strang, and C. Linnhoff-Popien, "A context modeling survey," In Workshop on advanced context modelling, reasoning and management, UbiComp, volumn 4, pp. 34-41, 2004.

[7] C. Bettini, O. Brdiczka, K. Henricksen, J. Indulska, D. Nicklas, A. Ranganathan, and D. Riboni, "A survey of context modelling and reasoning techniques," Pervasive and Mobile Computing, volumn 6, number 2, pp. 161-180, 2010.

[8] G. Adomavicius, and A. Tuzhilin, "Context-aware recommender systems," In Recommender systems handbook, pp. 217-253. Springer, Boston, MA, 2011.

[9] T. Gu, X.H. Wang, H.K. Pung, and D.Q. Zhang, "An ontology-based context model in intelligent environments," In Proceedings of communication networks and distributed systems modeling and simulation conference, volumn 2004, pp. 270-275, 2004.

[10] A. Gómez-Pérez, and O. Corcho, "Ontology languages for the semantic web," IEEE Intelligent systems, volumn 17, number 1, pp. 54-60, 2002.

[11] D.L. McGuinness, and F. Van Harmelen, "OWL web ontology language overview," W3C recommendation, volumn 10 , number 10 , 2004.

[12] L. San Martín-Rodríguez, M.D. Beaulieu, D. D'Amour, and M. Ferrada-Videla, "The determinants of successful collaboration: a review of theoretical and empirical studies," Journal of interprofessional care, 19(sup1), pp. 132-147, 2005.

[13] J. Bruneel, P. D'Este, and A. Salter, "Investigating the factors that diminish the barriers to university-industry collaboration," Research policy, volumn 39, number 7, pp. 858-868, 2010.

[14] N. Hara, P. Solomon, S.L. Kim, and D.H. Sonnenwald, "An emerging view of scientific collaboration: Scientists' perspectives on collaboration and factors that impact collaboration," Journal of the American Society for Information science and Technology, volumn 54, number 10, pp. 952-965, 2003.

[15] H. Patel, M. Pettitt, M., J.R. Wilson, "Factors of collaborative working: A framework for a collaboration model," Applied ergonomics, volumn 43, number 1, pp. 1-26, 2012.

[16] M. Doherty, "Factors of Successful Collaboration," 2015.

[17] P.W. Mattessich, and B.R. Monsey, "Collaboration: what makes it work. A review of research literature on factors influencing successful collaboration," Amherst H. Wilder Foundation, 919 Lafond, St. Paul, MN 55104, 1992.

[18] E. Taylor-Powell, and B. Rossing, "Evaluating collaborations: Challenges and methods," 2009.

[19] L. Buriano, M. Marchetti, F. Carmagnola, F Cena, C. Gena, and I. Torre, "The role of ontologies in context-aware recommender systems," In Mobile Data Management, 2006. MDM 2006. 7th International Conference, pp. 80-80. IEEE, 2006.

[20] H. Chen, T. Finin, and A. Joshi, "An ontology for context-aware pervasive computing environments," The knowledge engineering review, volumn 18, number 3, pp. 197-207, 2003.

[21] I. Oliveira, L. Tinoca, and A. Pereira, "Online group work patterns: How to promote a successful collaboration," Computers \& Education, volumn 57, number 1, pp. 1348-1357, 2011.

[22] J. Kotlarsky, and I. Oshri, "Social ties, knowledge sharing and successful collaboration in globally distributed system development projects," European Journal of Information Systems, volumn 14, number 1, pp. 37-48, 2005.

[23] C. Brewster, and K. O'Hara, "Knowledge representation with ontologies: Present challenges-Future possibilities," International Journal of Human-Computer Studies, volumn 65, number 7, pp. 563$568,2007$.

[24] J. Heflin, "OWL Web Ontology Language-Use Cases and Requirements," W3C Recommendation, volumn 10, p. 12, 2004.

[25] R. Studer, V.R. Benjamins, and D. Fensel, "Knowledge engineering: principles and methods," Data and knowledge engineering, volumn 25, number 1, pp. 161-198, 1998.

[26] L. Obrst, "Ontologies for semantically interoperable systems," In Proceedings of the twelfth international conference on Information and knowledge management, pp. 366-369. ACM, 2003.

[27] Z. Yu, Y. Nakamura, S. Jang, S. Kajita, and K. Mase, "Ontologybased semantic recommendation for context-aware e-learning," In International Conference on Ubiquitous Intelligence and Computing, pp. 898-907. Springer, Berlin, Heidelberg, 2007.

[28] J.S. Olson, S.K. Card, T.K. Landauer, G.M. Olson, T. Malone, and J. Leggett, "Computer-supported co-operative work: research issues for the 90s," Behaviour \& Information Technology, volumn 12, number 2, pp. 115-129, 1993.

[29] P.H. Carstensen, and K. Schmidt, "Computer supported cooperative work: New challenges to systems design," In K. Itoh (Ed.), Handbook of Human Factors, 1999.

[30] M. Billinghurst, S. Weghorst, and T. Furness, "Shared space: An augmented reality approach for computer supported collaborative work," Virtual Reality, volumn 3, number 1, pp. 25-36, 1998.

[31] D.C. Neale, J.M. Carroll, and M.B. Rosson, "Evaluating computersupported cooperative work: models and frameworks," In Proceedings of the 2004 ACM conference on Computer supported cooperative work, pp. 112-121. ACM, 2004.

[32] L.M. Camarinha-Matos, and H. Afsarmanesh, "Collaborative networks: a new scientific discipline," Journal of intelligent manufacturing, volumn 16, number 4-5, pp. 439-452, 2005.

[33] M. Saleh, and M.H. Abel, "Moving from digital ecosystem to system of information systems," In Computer Supported Cooperative Work in Design (CSCWD), 2016 IEEE 20th International Conference, pp. 91-96, 2016.

[34] L.M. Camarinha-Matos, and H. Afsarmanesh, "Collaborative Networks: Value creation in a knowledge society," In proceedings of PRPLAMAT 2006 IFIP international conference on knowledge enterprise: Intelligent strategies in product design, manufacturing and management, pp. 26-40. Springer, China, 2006.

[35] L.M. Camarinha-Matos, and H. Afsarmanesh, "Collaboration forms," In: Collaborative networks reference modeling, pp. 51-66. Springer, New York, 2008.

[36] H. Afsarmanesh, E. Ermilova, S.S. Msanjila, and L.M. CamarinhaMatos, "Modeling and management of information supporting functional dimension of collaborative networks," In Transactions on Large-Scale Data-and Knowledge-Centered Systems I, pp. 1-37. Springer, Berlin, Heidelberg, 2009. 